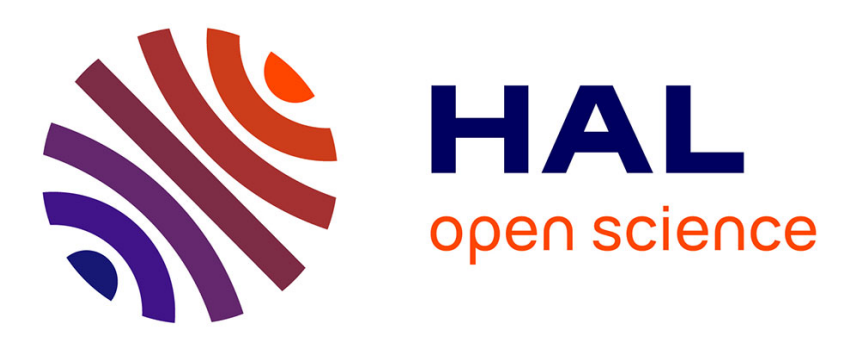

\title{
Auto-Emulsification of Water at Crude Oil/Water Interface: a Mechanism Driven By Osmotic Gradient
}

J. Duboué, M. Bourrel, E. Santanach Carreras, A. Klimenko, N. Agenet, N. Passade-Boupat, F. Lequeux

\section{- To cite this version:}

J. Duboué, M. Bourrel, E. Santanach Carreras, A. Klimenko, N. Agenet, et al.. Auto-Emulsification of Water at Crude Oil/Water Interface: a Mechanism Driven By Osmotic Gradient. Energy \& Fuels, 2019, 33 (8), pp.7020-7027. 10.1021/acs.energyfuels.9b00946 . hal-02392447

\section{HAL Id: hal-02392447 \\ https://hal.science/hal-02392447}

Submitted on 4 Dec 2019

HAL is a multi-disciplinary open access archive for the deposit and dissemination of scientific research documents, whether they are published or not. The documents may come from teaching and research institutions in France or abroad, or from public or private research centers.
L'archive ouverte pluridisciplinaire HAL, est destinée au dépôt et à la diffusion de documents scientifiques de niveau recherche, publiés ou non, émanant des établissements d'enseignement et de recherche français ou étrangers, des laboratoires publics ou privés. 


\title{
Auto-Emulsification of Water at Crude Oil/Water Interface: a Mechanism Driven By Osmotic Gradient.
}

\author{
J. Dubouée ${ }^{a, b,}$, M. Bourrel ${ }^{\mathrm{a}, \mathrm{b}}$, E. Santanach Carreras ${ }^{\mathrm{a}, \mathrm{b}}$, A. Klimenko ${ }^{\mathrm{a}, \mathrm{b}}$, N. Agenet ${ }^{\mathrm{e}}$, N. Passade- \\ Boupat $^{\mathrm{a}, \mathrm{b}}, \mathrm{F}$. Lequeux ${ }^{\mathrm{c}, \mathrm{d}, *}$
}

a) Laboratoire Physico-Chimie des Interfaces Complexes, Bâtiment CHEMSTARTUP, Route Départemental 817, 64170 Lacq, France

b) TOTAL SA, Pôle d'Etudes et Recherche de Lacq, BP 47, 64170 Lacq, France.

c) Laboratoire Sciences et Ingénierie de la Matière Molle, ESPCI Paris, PSL University,

Sorbonne Université, CNRS, F-75005 Paris, France

d) Laboratoire Physico-Chimie des Interfaces Complexes, ESPCI Paris, 10 rue Vauquelin, F-75231 Paris, France

e) TOTAL SA, Centre Scientifique et Technique Jean Féger (CSTJF), 64000 Pau, France.

*to whom correspondance should be addressed

\begin{abstract}
This work aims at studying the origin of spontaneous emulsification occurring at the oil/water interface. This phenomenon was observed for the five crude oils tested as well as at the interface of an asphaltene toluene mixture and water. The kinetics of appearance of water micro-droplets was slowed down for increasing salt concentrations and the micro-droplet formation ceases when the chemical potential of water they contain is equal to the one of the water in the bulk solution. Nucleation events occur at the oil-water interface and at the solid surface/liquid interface: some water microdroplets are stuck together close to the oil/water interface, others grow in oil and sediment or nucleate at the oil/solid surface. This suggests the following mechanism: water molecules diffuse from the water reservoir into the oil phase, and then create droplets. These droplets are simultaneously fed by hydrosoluble "osmogeneous" species increasing the osmotic pressure, inducing an osmotic pumping of water molecules into micro-droplets
\end{abstract}

\section{INTRODUCTION}

Enhanced Oil Recovery (EOR) by low salinity water receives a growing interest from the petroleum industry ${ }^{1,2}$. Most of previous researches on the subject focused on the rock/fluid interaction. Recently, the contribution of the fluid/fluid interactions to the underlying mechanism of the incremental oil recovery sometimes observed is also considered. The aim of this paper is to understand the physico-chemical mechanism at the origin of the formation of water droplet at the oil/water interfaces.

Droplets of water, also called "micro-dispersions", can spontaneously appear when oil is contacted with water without any stirring. The appearance of these "microdispersions" and their pertinence to the enhanced oil recovery by low salinity brine has been described. 3,4,5 The authors claim that the presence of these "microdispersions" can be used as a screening tool for selecting oils eligible to the low salinity process.

The objective of this paper is to investigate the underlying mechanism of "micro-dispersions" or microdroplets of water formation, which may have consequences, not only for low salinity EOR, but also on the measurement of several interfacial properties such as contact angles, interfacial tension, or interfacial rheology, etc... The viscoelasticity of the brine-crude oil interface has also been correlated to the oil recovery results, as ruling the oil snap-off mechanism in porous media. ${ }^{6,7}$

Actually, the spontaneous formation of micro-droplets of water in oil is reminiscent of the well-known spontaneous emulsification phenomenon. The first observation of spontaneous emulsification has been reported in 1878: $\mathrm{Gad}^{8}$ observed that oil droplets spontaneously form in an alkaline solution which is contacted to an oleic solution of lauric acid. The solution reacts with acids and produces a detergent lowering the interfacial tension and contributing to the droplet formation. Recently, S. Bochner de Araujo et al. ${ }^{9}$ highlighted that when a solution of asphaltenes dissolved in toluene is contacted with water, water micro-droplets form into the oil. Silva et al. ${ }^{10}$ have also observed that spontaneous emulsification of water in oil can occur even if interfacial tension is not ultra-low for a kerosene/surfactant (SPAN 80)/water system.

Two main possible mechanisms are usually cited as responsible for the spontaneous emulsification: interfacial turbulence, and diffusion and stranding. Interfacial turbulence results from the Marangoni effect and takes place as local interfacial tension gradients induce interfacial flows sufficient to produce droplets formation. Diffusion and stranding happens when one of the components of one phase has a very strong affinity for the other and quickly partitions into it. During the transfer, one of the constituent is "stranded" by the other and then separates out of phase.

Quincke ${ }^{11}$ explained that Gad's observations were due to localized interfacial tension gradients generated by the non-uniform distribution of the surfactant molecules along the interface. One liquid is injected into the other 
liquid under threads forms, which disintegrate into droplets.

Another mechanism was proposed for spontaneous emulsification (Gurwitsch ${ }^{12}$ ). The interfacial formation of surfactant is not necessary. Spontaneous emulsification phenomenon can appear when a water soluble component such as alcohol is added to the oil and then contacted with water. The alcohol diffuses through the interface and is accompanied with some oil that is soluble in the alcohol/water mixture. However, as the alcohol diffuses in the water phase, the oil solubility decreases. Thus, the oil emulsifies into the water phase. Later, Davies and Rideal'13 precised this mechanism and called it "diffusion and stranding". ${ }^{+4}$ Ruschak and Miller ${ }^{14}$ and Granek et al. ${ }^{15}$ have provided a theoretical treatment of the "diffusion and stranding" mechanism. Ruschak and Miller explained that spontaneous emulsification in partially miscible ternary systems such as toluene/water/solute systems occurs due to diffusion producing a region of local super-saturation near the interface. ${ }^{14}$ This effect can be observed in various systems $\left(\operatorname{Tan}^{16}\right)$ and it has been called "Ouzo effect" more recently by Vitale $^{17}$ et al.

However, some situations of spontaneous emulsifications are driven by "interfacial turbulence". Scriven and Sternling ${ }^{18}$ gave a mathematical model and established criteria predicting the occurrence of interfacial turbulence based on the Marangoni effect. They explained the Marangoni effect based on a lateral and normal concentration gradient. Ruckenstein and Berbente ${ }^{19}$ used the hydrodynamic instability theory to underline the conditions under which the Marangoni effect produces interfacial turbulence. These conditions of instability are considered in case of diffusion accompanied by chemical reaction: Davies and Rideal ${ }^{13}$ mentioned the interfacial turbulence as a possible mechanism of spontaneous emulsification, alternatively to "diffusion and stranding". Rubin and Radke $^{20}$, studying an acidic oil and alkaline solution system for which the interfacial tension was low, hypothesized that interfacial turbulence was a possible mechanism for spontaneous emulsification.

Rudin and Wasan ${ }^{21}$ worked on the spontaneous emulsification that takes place between an alkaline solution and an oil containing an organic acid. They explained that the "roll cells" they observed are due to interfacial turbulence, which is "a necessary but not sufficient condition” for spontaneous emulsification.

Dabros et al. ${ }^{22}$ observed the phenomenon of spontaneous emulsification with solutions of bitumen in heptane toluene mixtures (heptol). They proposed that destructive hydrodynamic stresses can occur, involving interfacial destabilization. The interface crumples upon

\section{Table 1. Properties of the crude oils}

ND: Not Defined area compression for a low concentration of bitumen in heptol. At high concentration of bitumen, they observed that, after a deflation, small water droplets detach from the surface of the main droplet of water that is in contact with oil.

Recently, S. Bochner de Araujo et al.9, studying asphaltene solutions in toluene contacted to water, have presented the interfacial turbulence as being the main mechanism of formation of the micro-droplets of water inside the oil. They have studied the stability of water-inoil and oil-in-water emulsions and more particularly the coalescence phenomenon.

However, some other mechanisms have been suggested recently: P. Silva et al. ${ }^{10}$ have studied a model system composed of kerosene and a non-ionic surfactant (SPAN 8o), and observed that micro-droplets of water appear in the oil phase when contacted with water. The interfacial tension measured is not lower than $4 \mathrm{mN} / \mathrm{m}$, thus, according to the authors, it is not because of very low interfacial tension that the micro-droplets are formed, but rather by "solubilization of water molecules" in the kerosene that the inverse micelle in the oil phase appears.

Lastly, spontaneous emulsification at the crude oil/water interface may be responsible for some dewetting, if a solid interface is in the vicinity of the water oil interface. Bartels et $\mathrm{al}^{23}$ have observed through the study of glass micromodels, that "dewetting patterns" were formed at the solid/liquid interface during both high-salinity and lowsalinity flooding with crude oil. They hypothesized that coalescence of these dewetting patterns yields a continuous water film and could explain, in some cases, the observed higher oil recovery. It can be speculated that the "dewetting patterns" mentioned by Bartels et al. could be the water micro-droplets formed spontaneously when crude oil is gently contacted with water. S. B. Fredriksen et al. ${ }^{24,} 25$ explained that oil can be displaced and mobilized by diffusion and osmosis. They studied, at pore scale level, the displacement of oil in presence of a salt concentration gradient. They showed that the oil can be considered as a semi-permeable membrane: water diffuses from low salinity water pockets to high salinity water, inflating the high salinity water film and mobilizing the oil.

In this article, based on various observations, we will show that the auto-emulsification of water in oil results from an osmotic effect that we will explicit further on.

\section{MATERIALS AND METHODS}

\section{MATERIALS}

In this study, we have used five crude oils. Their properties are detailed in Table 1 . We chose crude oils with 


\begin{tabular}{|l|ll|l|l|l|l|}
\hline Crude & $\begin{array}{l}\text { Viscosity } \\
\left.50^{\circ} \mathrm{C}\right)\end{array}$ & Type & $\begin{array}{l}\mathrm{pHf}, 1 \mathrm{~g} / \mathrm{L} \\
\mathrm{NaCl}\end{array}$ & $\begin{array}{l}\mathrm{pHf}, 100 \mathrm{~g} / \mathrm{L} \\
\mathrm{NaCl}\end{array}$ & $\begin{array}{l}\text { Time of appearance of the "brownish" phase } \\
\text { for deionized water (h) }\end{array}$ \\
\hline A & 4.5 & Acido-basic & 4.0 & 3.8 & $0.25 \pm 0.1$ \\
\hline B & 44.8 & Acidic & 6.7 & 6.9 & $1.7 \pm 0.4$ \\
\hline C & 6.6 & Acidic & 6.5 & 6.8 & $1.9 \pm 0.9$ \\
\hline D & 2.9 & Acido-basic & 4.5 & 3.9 & $0.25 \pm 0.2$ \\
\hline E & 11,000 & Acidic & ND & ND & $>>48$ \\
\hline $\begin{array}{l}\text { E with } 15 \% \\
\text { toluene }\end{array}$ & 100 & Acidic & ND & ND & $30 \pm 1$ \\
\hline
\end{tabular}

Table 2. Compositions of water with mono and divalent cations (constant percentage of $65.8 \% \mathrm{Na}^{+}$, $26.1 \% \mathrm{Ca}^{2+}$ and $\left.8.1 \% \mathrm{Mg}^{2+}\right)$.

Note: the osmotic pressure has been calculated for a solution considered as real.

\begin{tabular}{|l|l|l|l|l|}
\hline Name & $\begin{array}{l}\mathrm{NaCl} \\
(\mathrm{g} / \mathrm{L})\end{array}$ & $\begin{array}{l}\mathrm{CaCl}_{2} \cdot 2 \mathrm{H}_{2} \mathrm{O} \\
(\mathrm{g} / \mathrm{L})\end{array}$ & $\begin{array}{l}\mathrm{MgCl}_{2} \cdot 6 \mathrm{H}_{2} \mathrm{O} \\
(\mathrm{g} / \mathrm{L})\end{array}$ & $\begin{array}{l}\text { Osmotic pressure } \\
(\mathrm{bar})\end{array}$ \\
\hline $\begin{array}{l}\text { Divalent } \\
\text { brine 167 }\end{array}$ & 109.89 & 43.59 & 13.53 & 146.7 \\
\hline $\begin{array}{l}\text { Divalent } \\
\text { brine 10 }\end{array}$ & 6.58 & 2.61 & 0.81 & 7.4 \\
\hline $\begin{array}{l}\text { Divalent } \\
\text { brine 1 }\end{array}$ & 0.66 & 0.26 & 0.08 & 0.7 \\
\hline
\end{tabular}

various acido-basic properties using the notions of acidic and acido-basic oils which have been defined by N. Passade Boupat et al. ${ }^{26}$. The $\mathrm{pHf}$ represents the $\mathrm{pH}$ of a water solution that has been vigorously mixed by manual shaking with an equivalent volume of oil at room temperature.

As it will be introduced later, asphaltene solutions in toluene will also be used as hydrocarbon phase. The toluene is purchased from VWR, (GPR rectapur) and heptane is from Sigma-aldrich (reagentPlus)

Heptol is a mixture of $25 \%$ heptane, $75 \%$ toluene.

Asphaltenes are extracted from a Canadian oil sand using the following protocol:

Crude oil was precipitated in heptane with a ratio of 1:20 of oil in heptane. Then, in order to remove resins from the mix of asphaltenes, the precipitate was dissolved in toluene and then precipitated again in heptane at 1:40 ratio.

The heptane filtrate containing the de-asphaltenated crude oil was evaporated by azote stripping. The obtained hydrocarbon was then used in the study and referred to as "maltenes".

$\mathrm{NaCl}$ solutions have been used, at conditions indicated in the text. Besides, the effect of divalent cations has been investigated with the aqueous solutions defined in Table 2.

D-(+)-Glucose was purchased from Sigma Aldrich, purity $\geq 99.5 \%$. In order to be at an osmotic equivalent pressure equivalent to Divalent brine 167, a concentration of $843.9 \mathrm{~g} / \mathrm{L}$ of glucose was used.
The tests with crude oils were done at $50^{\circ} \mathrm{C}$ temperature and the temperature was remained constant during the experiment. However, the tests with asphaltenes were done at ambiant temperature. All the containers (tubes) are carefully sealed.

\section{METHODS}

Macroscopic observation

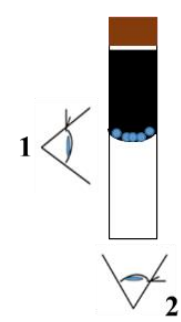

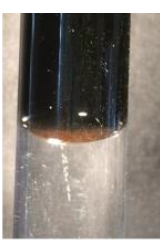

1

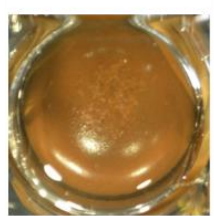

2

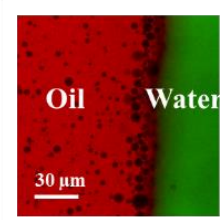

3
Figure 1. Observation of the "brownish phase" formed when the crude oil A is contacted with deionized water without any agitation. Left picture: diagram of the set-up. Picture 1: side view of the tube. Picture 2: view from the bottom of the tube. Picture 3: confocal microscopy image of the oil/water interface, plane (XY) at $\mathrm{z}=\mathrm{o} \mu \mathrm{m}$ height (see Figure 7 for axis definition), fluorophore in water: fluorescein.

Oil is gently poured on top of water without any agitation. After some time, as seen by naked eyes, a "brownish phase" appears spontaneously at the interface, in the oil phase, similarly to what has previously been 
reported 3 . In Figure 1 (pictures 1 and 2), side and bottom views of the formation of the "brownish phase" can be observed: it is formed by an assembly of droplets. This apparition of micro-droplets of water at the oil/water interface has been mapped over time. For this, $10 \mathrm{~g}$ of water solutions of different salinities - from o g/L to $300 \mathrm{~g} / \mathrm{L} \mathrm{NaCl}$ - have gently been contacted in test tubes with $5 \mathrm{~g}$ of four different crudes: A, B, C and D. As it was observed that temperature accelerates the spontaneous emulsification, the test tubes were placed in an oven at $50^{\circ} \mathrm{C}$. To obtain the diagrams, photographs were taken regularly from below and from the side, as shown typically in Figure 1 (pictures 1 and 2). The criterion used for the appearance of the droplets was a change of color detected by naked eyes. Using quantitative colorimetry was not pertinent because of the intrinsic variability of adsorption of the oil used.

\section{Microscopic observation}

To observe at the microscopic scale, a glass capillary (rectangular section, $50 \mu \mathrm{m}$ high and $1 \mathrm{~mm}$ wide) has been made oil wet by treatment with a solution of $0.5 \%$ chlorodimethyl-octadecylsilane (CAS 18643-08-08) in dichloromethane, followed by drying. Then, crude oil is introduced in the capillary tube by capillary rise, before being displaced by water injection through the same inlet. Both sides of the capillary are glued with epoxy ("epoxy adhesive Loctite EA9492”) to limit leakage. A confocal microscope is used for a $3 \mathrm{D}$-observation with a depth of field of $0.56 \mu \mathrm{m}$ as illustrated in Figure 1 (picture 3). An observation at different height (axis Z) is done and slices of the oil/water interface are obtained through the XY plane. Besides, a transmission microscope has been used to obtain the images shown on Figure 6. The objective used for the confocal and transmission microscopes are oil immersion objectives $\times 40$ with a numerical aperture of 1.3.

In order to observe the micro-droplets inside the oil, different chromophores have been used: rhodamine $6 \mathrm{G}$ or fluorescein in water, or Nile red in oil. Besides, their possible impact on micro-droplets formation and its kinetics has been checked: it has been found inexistant for Nile red with the concentration used, whereas the formation of micro-droplets is strongly slowed down with a high concentration of fluorescein ("salt" effect of the fluorescein).

To investigate the mechanism of formation of the microdroplets, fluorescent charged nano particles have been dispersed in water. Nano-particles $(20 \mathrm{~nm}$ diameter, "Fluospheres, yellow-green") grafted with carboxylate function in one case, and with an amine-modified function in another case were used. These experiments were carried out on the model system ( $2 \%$ asphaltenes in toluene) as well as on crude oil A. For both systems, the oil phase rises in one side by capillary forces in a flat capillary of $50 \mu \mathrm{m} \times$ $2 \mathrm{~mm}$ section as described above. Then, the aqueous solution containing 20,000 ppm (respectively 2,000 ppm and $100 \mathrm{ppm}$ ) of fluorescent particles is injected by the same side. These flat capillaries are then glued on a glass slide. They are observed by confocal microscopy to determine if particles are embedded in the micro-droplets in the oil phase, or if they stay in the water phase.

To quantitatively measure the penetration of the water into the oil, the length of the layer composed of the water micro-droplets stuck to the oil-water interface is measured over time, for the model system: $5 \%$ and $1 \%$ asphaltenes in toluene. For this, pictures are taken by transmission microscopy (oil immersion objectives $\times 40$ with a numerical aperture of 1.3) at mid-height of the sample $(\sim 25 \mu \mathrm{m})$. The thickness of the droplets layer is the distance between the last droplet apex and the macroscopic interfaces, average over all the droplets at mid height of the interface. For each thickness at a given time, 6 samples have been used to yield an averaged measurement.

\section{Vapor contact experiments}

In order to investigate the relevance of the interfacial turbulence for the spontaneous emulsification at the water/oil interface, asphaltenes solutions ( $1 \%$ and $5 \%$ ) in toluene have been enclosed in a tight-closed cell, in presence of an atmosphere saturated both in water and toluene (see Figure 4 ). The water uptake of the asphaltene solution is measured by Karl Fischer analysis over time (see Table 3). The whole sample is recovered and stirred with an automatic stirrer for at least 2 minutes and then a small amount of the bottom of the sample is taken and submitted to Karl Fischer analysis.

\section{RESULTS}

The phenomenon of spontaneous emulsification at the water-crude oil interface was studied for different oil type (acidic or acido-basic) and by varying the oil viscosity. Then, the effect of the salinity on the kinetics of microdroplets appearance and disappearance was scrutinized. Besides, a model system has been established allowing to replace the crude oil by a more simple system.

In a second time, the mechanism of formation of water micro-droplets was studied through two experiments: one using vapor of water and the other with fluorescent nanoparticles. Lastly, the structuration of the water microdroplets close to the water-oil interface and solid-liquid was investigated.

\section{Spontaneous emulsification at the water- crude oil interface}

As seen in Figure 1, the "brownish phase" which appears at the oil/water interface consists in vesicles of water dispersed in the oil phase, as already recognized by others 3 .

The micro-droplets of water appear whatever the characteristics of the oil (acidic or acido-basic oil as specified in Table 1 ).

Considering the viscous crude oil E, no "brownish phase" is formed after 48 hours of contact at $50^{\circ} \mathrm{C}$ with low salinity water (water $+2 \mathrm{~g} / \mathrm{L} \mathrm{NaCl}$ ); yet when viscosity is decreased to $100 \mathrm{cP}$ by dilution with toluene, a "brownish phase" appears within 48 hours. As a result, it can be concluded 
that increasing the viscosity of the oil slows down the formation of the water micro-droplets.

The time required for micro-droplets appearance is plotted in Figure 2 against the ionic strength $(\mathrm{mol} / \mathrm{L})$ of the aqueous phase containing from o to $300 \mathrm{~g} / \mathrm{L}$ and Divalent brine (containing divalent cations; see Table 2 ).

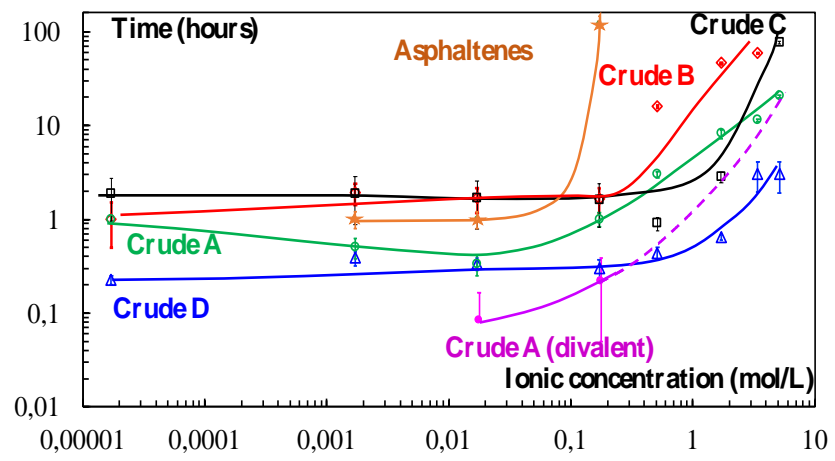

Figure 2. Evolution of the time of appearance of the "brownish phase" in tubes with a ratio of $5 \mathrm{~g}$ of crude oil to $10 \mathrm{~g}$ of water at different salinities for four different crude oils (at $50^{\circ} \mathrm{C}$ ) and for the model system (at $23^{\circ} \mathrm{C}$ ) $1 \%$ asphaltenes - toluene (see: Table 1). The two purple dots refers to Divalent brine 1 and Divalent brine 10 (see Table 2). Note: the ionic strength of $10^{-}$ $5 \mathrm{~mol} / \mathrm{L}$ corresponds to the salinity of deionized water and is used for convenience in the log-log representation. Lines are guides for the eyes.

It was noticed that with the different crude oils tested, either acidic or acido-basic, the higher the salinity, the longer it takes to observe the micro-droplet appearance at the oil/water interface. The same overall pattern is displayed by all crudes upon increasing $\mathrm{NaCl}$ concentration: no visible change until osmotic pressure reaches 10 bar and an increase of the time of appearance for higher salinity.

For crudes A and D which are both acido-basic, the "brownish phase" appearance occurs at a slightly lower ionic strength comparing to the acidic crude $\mathrm{B}$ and $\mathrm{C}$ (see Table 1).

Figure 2 shows that Divalent brine 167 does not produce water micro-droplet formation after 100 hours. It appears that for a high concentration of monovalent and divalent cations, the formation of water micro-droplets is inhibited or at least is strongly slowed down.

The question can be raised as to know whether the micro-droplets formed at low salinity can disappear if contacted again with high salinity water. To study this phenomenon, $5 \mathrm{~g}$ of crude oil B were contacted with $10 \mathrm{~g}$ of water containing $10 \mathrm{~g} / \mathrm{L} \mathrm{NaCl}$ in a $20-\mathrm{mL}$ tube during $\sim 42$ hours, and $5 \mathrm{~g}$ of the same oil B were contacted with a 300 $\mathrm{g} / \mathrm{L} \mathrm{NaCl}$ brine (for which no micro-droplets had been observed to form after a comparable duration). Then, we gently replaced the $10 \mathrm{~g} / \mathrm{L} \mathrm{NaCl}$ brine of the first tube by the $300 \mathrm{~g} / \mathrm{L} \mathrm{NaCl}$ brine from the second tube without destroying the "brownish phase" and observed over time.
We observed that the micro-droplets disappeared when the low salinity water in contact with the oil is replaced by high salinity water. The disappearance can be noticed within a few tenth of minutes. Pictures are shown in Figure 3. This demonstrates that the phenomenon leading to the appearance of micro-droplets is reversible.

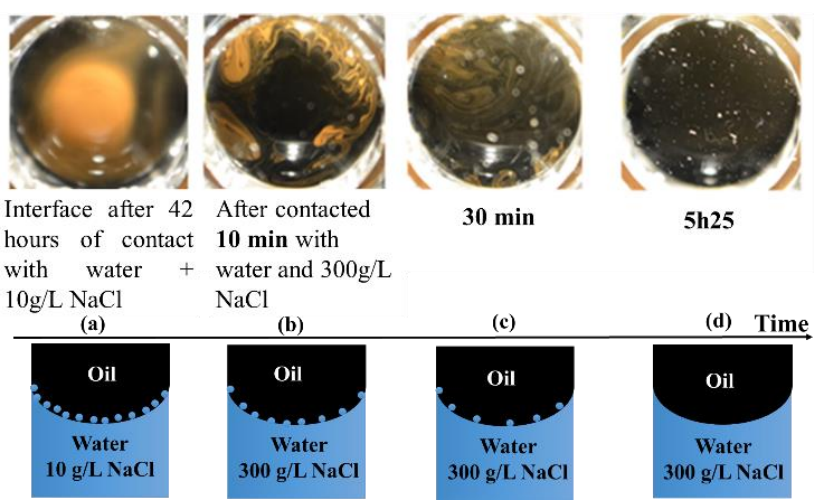

Figure 3. Pictures of the interface from below for the reversibility test: after $42 \mathrm{~h}$ of contact with low salinity water (a) and after contact with high salinity water that had been pre-equilibrated with the crude oil B (b, c, d).

Spontaneous emulsification at the water/toluene-asphaltene interface: kinetics

In order to avoid the complexity of crude oil systems, we used a model system composed of a solution of asphaltenes in toluene, as defined in Method section.

When asphaltenes are solubilized in toluene and further contacted with water without any agitation, water microdroplets form spontaneously in the oil phase (see Figure 6) similarly to crude oils. The same observation was also reported recently 9 . The model system follows in fact the same trends as for the crude oil shown in Figure 2: the appearance of micro-droplets is delayed by salinity in the same manner as for crude oils (see Figure 2).

In order to explore the type of mechanism underlying the formation of the water micro-droplets, two types of experiments were carried out: one with asphaltene solution in contact with water vapor, the other one with asphaltene solution contacted with water containing fluorescent solid nanoparticles.

Asphaltenes solution in contact with water vapor

The design of the experiment is given in Figure 4.

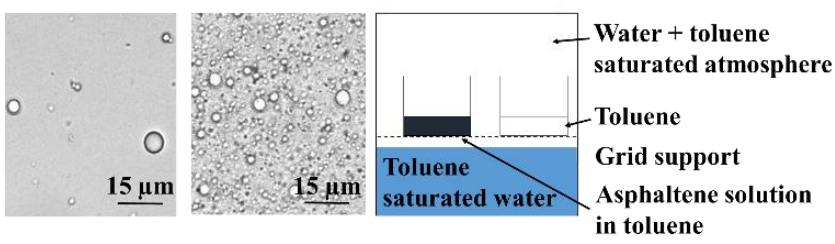

Figure 4. Observation by transmission microscopy of $1 \%$ (left) and $5 \%$ (middle) asphaltenes solutions in toluene after 34 days of contact with water vapor. Diagram of the set-up (right). Room temperature. 
In this experiment, there is no liquid/liquid interface. The asphaltene solution is in contact only with vapor, as explained in the Method section.

The water uptake from vapor of the asphaltenes solutions after 34 days is given in Table 3 .

Table 3. Water uptake of asphaltene solutions from vapor phase. $R$ is the water/asphaltene molar ratio calculated by taking $750 \mathrm{~g} / \mathrm{mol}$ for the asphaltenes. ${ }^{27}$

\begin{tabular}{|l|l|l|l|}
\hline $\begin{array}{l}\text { Asphaltenes } \\
\text { concentration }\end{array}$ & $\begin{array}{l}\text { Water } \\
\text { uptake } \mathrm{t}=\mathrm{o} \\
(\mathrm{ppm})\end{array}$ & $\begin{array}{l}\text { Water } \\
\text { uptake } \mathrm{t}=34 \\
\text { days }(\mathrm{ppm})\end{array}$ & $\begin{array}{l}\mathrm{R} \\
(\text { mole/mole }) \\
\mathrm{t}=34 \text { days }\end{array}$ \\
\hline $1 \%$ & 340 & $1,900 \pm 100$ & $\sim 8$ \\
\hline $5 \%$ & 340 & $8,000 \pm 100$ & $\sim 7$ \\
\hline
\end{tabular}

The water concentration in the asphaltene solution after 34 days is obviously much higher than the solubility limit in toluene ( $500 \mathrm{ppm})$, which is in agreement with. ${ }^{28}$

Then, samples of the $1 \%$ and $5 \%$ asphaltenes solutions in toluene were observed by transmission microscopy. Pictures (Figure 4) show water micro-droplets at the bottom of the oil container. Droplets with diameters up to $\sim 8 \mu \mathrm{m}$ formed in that case. The mechanism of formation is initiated by condensation of water in toluene, yet the droplets formed are similar to those formed in the case of a liquid water/oil interface. The water molecules contributing to the apparent molar ratio of water/toluene account both for the water contained in the micro-droplet and for the water molecules dissolved in toluene bulk. Consequently, the molar ratio $\mathrm{R}$ is corrected for this effect and only takes into account the water molecules in excess compared to the experimental solubility ( $340 \mathrm{ppm})$. This experiment shows that the water micro-droplets can be formed by water vapor condensation. It is in agreement with D. S. Khvostichenko et al. ${ }^{29}$ who used FTIR to investigate the state of water in crude oil contacted with water.

To investigate if the mechanism of interfacial turbulence should be taken into consideration, fluorescent nanoparticles (with carboxylate or amine functionalization) were added in water.

The oil/water interface was examined using a confocal microscope (Figure 5). No fluorescence is observed inside the water micro-droplets, showing that the nanoparticles were not transferred to the oil phase. We have checked that water micro-droplets formed by stirring display fluorescence.

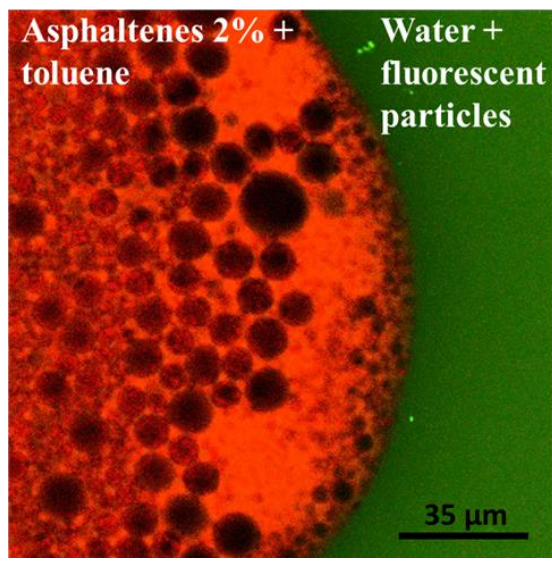

Figure 5. A confocal microscopy view of the water/oil interface. Oil: $2 \%$ asphaltenes in toluene; deionized water and fluorescent particles (20,000 ppm, size $20 \mathrm{~nm}$ ); (XY) plane at $\mathrm{z} \approx \mathrm{o} \mu \mathrm{m}$ height (see Figure 6 for axis definition). Fluorescent nanoparticles present in the water phase (right of the picture) are not present in the droplets embedded in the oil phase (left or the picture).

From the results of the two above experiments, it can be concluded that, in the present case, the water microdroplets are not formed by any surface motion, but simply by diffusion of individual water molecules inside the oily phase that aggregate to create a dispersed water phase after some time.

Spontaneous emulsification at the water/toluene-asphaltene interface: structuration of the water micro-droplets

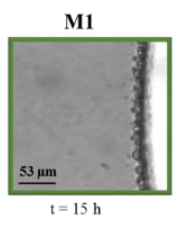

M3

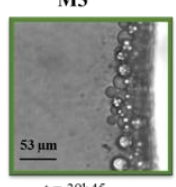

$\mathrm{t}=39 \mathrm{~h} 45$

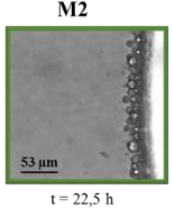

M4

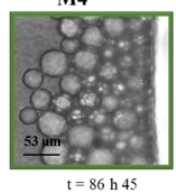

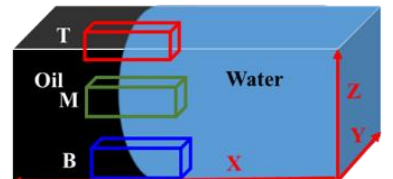

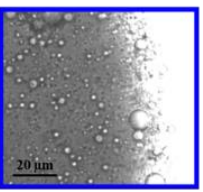

B $\quad \mathrm{t}=4 \mathrm{~h}$

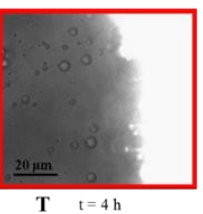

T $\quad \mathrm{t}=4 \mathrm{~h}$
Figure 6. A transmission microscopy view of the water-oil interface in the (XY) planes. Figure $\mathrm{M}_{1}, \mathrm{M}_{2}, \mathrm{M}_{3}, \mathrm{M}_{4}$ : oil ( $1 \%$ asphaltenes in toluene); o.o1 $\mathrm{g} / \mathrm{L} \mathrm{NaCl}$; at different times of contact; $(\mathrm{XY})$ plane at height $\mathrm{z} \approx 25 \mu \mathrm{m}$ (mid height). Figure $\mathrm{B}$ : oil ( $5 \%$ asphaltenes in heptol); o.o1 g/L NaCl; 4 h of contact; (XY) plane at height $\mathrm{z} \approx 0 \mu \mathrm{m}$. Figure $\mathrm{T}$ : oil ( $5 \%$ asphaltenes in heptol); $0.01 \mathrm{~g} / \mathrm{L} \mathrm{NaCl} ; 4$ h of contact; (XY) plane at height $\mathrm{z} \approx$ $50 \mu \mathrm{m}$. All systems studied at room temperature.

As seen in Figure 6 (picture B), water micro-droplets formed in the hydrocarbon phase sediment, and thus accumulate at the bottom of the capillary tube. This explains the difference of droplets density between the top and the bottom glass surface. 
This experiment has also allowed to see that water micro-droplets stick at the glass/liquid interface (Figure 6, picture T), despite its oil-wet characteristics, indicating nucleation growth at this interface.

Figure 6 (pictures $M$ ) shows that some particles can remain attached to the water/oil interface and do not fall down to the bottom side of the capillary. It has been checked that the water micro-droplets are not retained by water droplets located below and above but are attached to micro-droplets closer to the oil/water interface.

For confirmation, one capillary tube has been observed and then flipped upside-down, let in this position for 10 min, and flipped back to the initial position. The confocal microscopy observation showed that the particles were still attached to the interface, exactly in the same configuration as before. The water micro-droplets layer adherence at the interface originates from the adhesion between them. Additionally, some water micro-droplets sediment and others nucleate at the solid-liquid interface.

To properly estimate the thickness of the micro-droplet layer, we used hydrophobic glass capillary tube as described in Method section (see Microscopic observation) and used capillary rise to sequentially fill it with oil and water. The interfacial zone was examined.

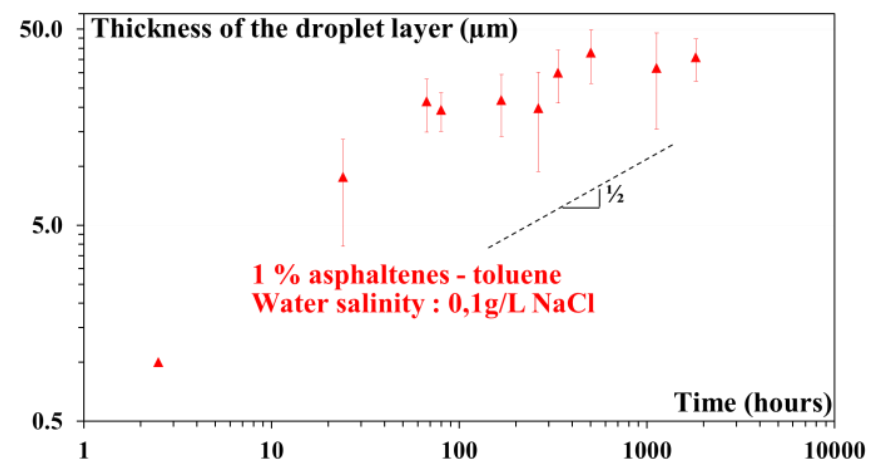

Figure 7. Evolution of the thickness of water micro-droplets layer versus the time for the model system $(5 \%$ and $1 \%$ asphaltenes in toluene); brine salinity: $0.1 \mathrm{~g} / \mathrm{L} \mathrm{NaCl}$.
The thickness of the water micro-droplets layer accumulating at the water-oil interface was measured over time for $1 \%$ asphaltenes in toluene and a brine salinity of $0.1 \mathrm{~g} / \mathrm{L} \mathrm{NaCl}$ (Figure 7). The average slope of the curve in the log-log representation is likely compatible with $1 / 2$ slope at the beginning of the swelling, suggesting a diffusioncontrolled mechanism for the water penetration. However, the apparent exponent seems to decrease after 500 hours.

\section{DISCUSSION}

The apparition of micro-droplets without oil/water interface discards the explanation involving interfacial turbulence. Flow at the interface is not necessary to observe the apparition of droplets. In addition, even in the presence of a water/oil interface, no flow even at very small scale were observed during the formation of the microdroplets. This is reinforced by the fact that nanoparticles present in the water are not incorporated in the microdroplets.

These experimental facts thus suggest a diffusion-driven mechanism of the water as the first step for the spontaneous formation of the micro-droplets: the individual water molecules that dissolve in the oil phase may condense into micro droplets in a second step.

This condensation is governed by an osmotic pressure phenomenon. Indeed, we have seen that the droplets deflate when salinity of the brine in contact is increased, as shown in (Figure 3).

Besides, an adverse effect of salt concentration is observed: the more salt is added, the more the process slows down. This incidentally suggests that the osmotic pressure in the water micro-droplets is high. When these droplets are close to the macroscopic water interface, there are water molecules that diffuse across the oil phase until the chemical potential of the water into the micro-droplets and that of the water in the reservoir equilibrate. The appearance of the micro-droplets, as well as the radius of the water micro-droplets, depend on the osmotic pressure resulting from the difference between the chemical potential of the water molecules in the bulk water and in 

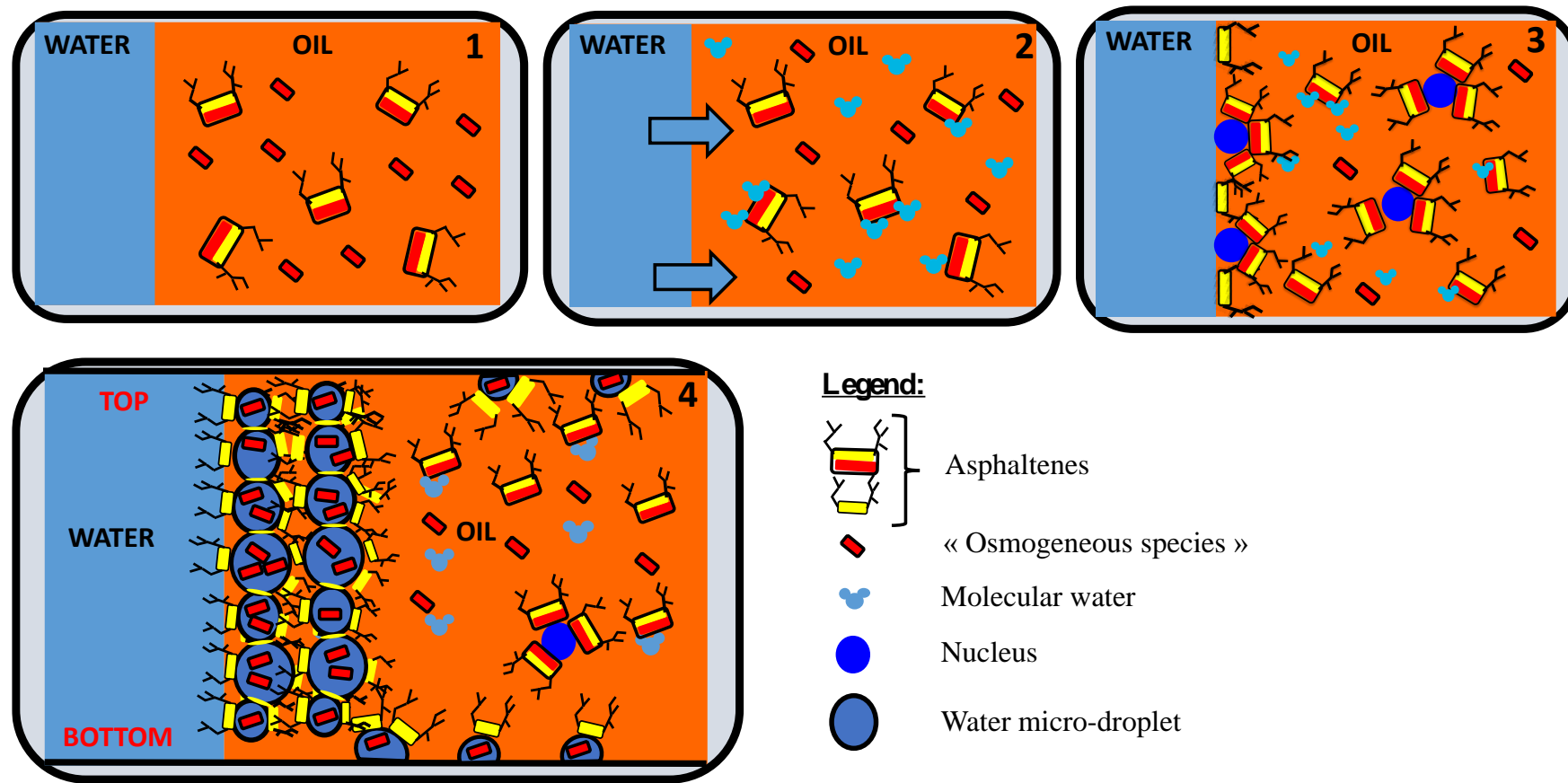

Figure 8. Diagram of the mechanism of formation of the water micro-droplets in the oil phase.

the micro-droplets. As a consequence, the higher the salt concentration, the slower the increase in droplet radius; hence, the appearance time increases.

To confirm the previous hypothesis, a solution of glucose was prepared at an osmotic pressure equivalent to Divalent brine 167 . After this solution was contacted with crude oil A, no micro-droplets of water were formed within the same time scale $(\approx 100$ hours). This confirms the hypothesis of an osmosis-driven phenomenon. Therefore, the saltdependency of asphaltenes interfacial activity ${ }^{3}$ does not appear to be the root cause for micro-droplets formation.

The droplets formation requires that some species present in the oil phase have a reasonable solubility in water in order to increase the osmotic pressure. Indeed, partitioning of part of the asphaltenes set of molecules is well established by the fact that the $\mathrm{pH}$ of water in contact with crude oil exhibits a significant $\mathrm{pH}$ modification ${ }^{33}$. In our case we have observed $\mathrm{pH}$ change of the aqueous phase contacted with a solution of $5 \%$ asphaltenes in toluene, with the same volume of oil and water. The water $\mathrm{pH}$ initially of 5.6 evolved towards a value of 8.1 after two weeks, which means that molecules - mostly basic in this case - have partitioned into the water. Besides, UV analysis have also found that polyaromatic species were partitioning into water.

The results of these experiments show that the spontaneous formation of the water micro-droplets is governed by an osmotic phenomenon, due to the partitioning of some "osmogeneous" species such as ions that migrate into the water micro-droplet. Consequently, they increase the osmotic pressure in the droplet, inducing a migration of water molecules into the droplets. The droplets then swells because of water ingress, leading to the feeding of these droplets by other oil soluble species possessing an affinity for water. This process continues until an osmotic pressure equilibrium is reached.

The formation of water micro-droplets was also studied in de-asphaltenated crude oil ("maltenes"). The water micro-droplets are still formed but qualitatively (observation in glass tube) less than with the asphaltenes. Therefore some species in the crude oil, which not qualified as "asphaltenes", contribute to the formation of the water micro-droplets. Additionally, for viscous oil (oil E), the process is slower. We suggest that for viscous oil, the diffusion coefficient of water in oil is smaller compared to the other oils - so that the osmotic mechanism is slowed down. A schematic view of the mechanism is given in more details in Figure 8. By definition, asphaltenes are a set of molecules that are not soluble in heptane; however they exhibit a continuum of polarity. ${ }^{30}$ Some of them adsorb at the interface, yielding a decrease of interfacial tension. ${ }^{31}$ Others are partitioning into water, as indicated above.

Due to its partial solubility in oil, molecular water diffuses in the oil phase and is fixed by polar sites of asphaltenes. The solvation of asphaltenes by water decreases their stability in oil, and, as a consequence, they aggregate into clusters stuck together through the water molecules. Clustering goes on until a water nano-droplet is formed. The development of this droplet is submitted to two antagonistic effects: the Laplace pressure tends to decrease the water equilibrium concentration in the neighboring oil phase; but, on the other hand, an increase due to osmotic pressure in the droplets is induced by the dissolution of hydro-soluble "osmogeneous" species in the water. We can compare briefly the two effects. The Laplace pressure is $2 \gamma / R$ and decreases for increasing radius. Its 
effect is only present for small droplets - and leads to a deflation of the small droplets into the large one as observed for Ostwald ripening. For a given droplet size of typically $10 \mathrm{~nm}$ diameter which is the diameter of one asphaltene nano-aggregate ${ }^{34}$, this pressure is about $\mathrm{Pc} \approx 4$ $\times 10^{6} \mathrm{~Pa}$ (assuming $\gamma=20 \mathrm{mN} / \mathrm{m}$ ). This pressure is overcome by osmotic pressure for a concentration $\mathrm{n}=$ $\mathrm{Pc} /(\mathrm{R} \mathrm{T}) \approx 2 \mathrm{~mol} / \mathrm{L}$ which is equivalent to $120 \mathrm{~g} / \mathrm{L} \mathrm{NaCl}$. The growth of droplets as observed experimentally steps at 10 $\mathrm{g} / \mathrm{L}-100 \mathrm{~g} / \mathrm{L}$, so the osmotic pressure is more efficient than Laplace pressure and the droplets swell.

So the growths of droplets require the existence of water nuclei of diameter at least equal to $10 \mathrm{~nm}$. We suggest the following mechanism: the water molecules diffuses into the oil and encounter polar groups and ions of asphaltenes and fix to it. Then, these hydrated asphaltenes aggregate to others asphaltenes hydrated and a "nucleus" (very small droplet) is formed. For this a large nucleus need to be formed to overpass the Laplace pressure. To equalize the difference of potential between this "nucleus" and the water reservoir, water diffuse from the reservoir to the water micro-droplet.

Thus, water "nucleus" inflates by osmosis. The molecular water penetrates into the micro-droplet until the chemical potential of the water in the micro-droplet equals the one of the molecular water. Meanwhile, because the droplets swell, more and more oil soluble "osmogeneous" species (such as molecules or ions) can penetrate the droplets, thanks to the partitioning equilibrium of these species between oil and water droplets. Thus an osmotic pump inflates the droplets until the osmotic equilibrium between these droplets and the water reservoir.

Due to their proximity with the bulk water, the droplets close to the oil-water interface are the first one to grow. Because of the presence of "osmogeneous" species adsorbed at the interface, these droplets are stuck to it (Figure 6) and altogether, create a shell of droplets stuck at the interface. However, some droplets can also appear in the oil volume far from the water interface. These ones, denser than the oil phase, sediment at the bottom of the oil phase. Lastly, droplets also form at the glass-oil interface, likely because surface charges tend also to be solvated by water and thus surfaces exhibit nucleus sites for the droplet formation. These last ones remain stuck to the glass/oil interface. This observation could explain the "dewetting patterns" observed by Bartels et al.23. Thus, three types of droplets exist: some are stuck to the oil/water interface, others attached to the solid interfaces and lastly some others sediment at the bottom of the reservoir.

Through these different experiments, we show that the water micro-droplets spontaneously formed at the oil/water interface are the result of the diffusion of molecular water from the water reservoir, due to osmotic pumping. The water micro-droplets grow thanks to osmotic pressure that is generated by the migration of oil soluble "osmogeneous" species (such as molecules or ions) that can partition between water and oil. In that sense, the mechanism is different from the mechanism of diffusion and stranding. Additionally, it has been seen that the interfacial turbulence is not necessary for the formation of the micro-droplets.

\section{CONCLUSION}

The phenomenon of spontaneous emulsification has been observed for the five crude oils tested. The higher concentration of salt in bulk water, the longer the time of appearance of water micro-droplets. The asphaltenes are some of the species responsible for the spontaneous formation of water micro-droplets in the oil. Other species in the maltene fraction seem to play a similar role.

The molecular water diffuses in the oil and no interfacial motion contributes to the mechanism. It is a reversible mechanism governed by osmotic pressure. There is a portion of "osmogeneous" species (molecules or ions) that is soluble in water. These water-soluble species generate osmotic pressure in water droplets, and prime a water pump from the water phase into the water droplets embedded in the oil phase.

The consequences of this phenomenon on oil recovery has been addressed in the proceeding of IOR $2019^{35}$.

\section{AUTHOR INFORMATION}

\section{Corresponding Author \\ * E-mail: \\ jennifer.duboue@gmail.com \\ francois.lequeux@espci.fr}

\section{ACKNOWLEDGMENT}

The authors are grateful to TOTAL for permission to publish this work.

\section{REFERENCES}

1. S.-Y. Chen, Y. Kaufman, K. Kristiansen, D. Seo, A. M. Schrader, M. B. Alotaibi, H. A. Dobbs, Nicholas A. Cadirov, J. R. Boles, S. C. Ayirala, J. N. Israelachvili, and Ali A. Yousef; Effects of Salinity on Oil Recovery (the "Dilution Effect"): Experiemental and Theoretical Studies of Crude Oil/Brine/Carbonate Surface Restructuring and Associated Physicochemical Interactions; Energy and Fuels, 31, 8925-8941; 2017.

2. R. A. Nasralla, H. A. Nasr-El-Din; Impact of Electrical Surface Charges and Cation Exchange on Oil Recovery by Low Salinity Water; Society of Petroleum Engineers Asia Pacific Oil and Gas Conference and Exhibition, 20-22 September, Jakarta, Indonesia, 147937-MS; 2011.

3. A. Emadi, M. Sohrabi; Visual Investigation of Oil Recovery by Low Salinity Water Injection: Formation of Water MicroDispersions and Wettability Alteration; Proceeding at the Society of Petroleum Engineers Annual Technical Conference and Exhibition; New Orleans, Louisiana, USA; SPE 166435; 30 September - 2 October 2013 
4. J. M. F. Facanha, P. Mahzari, and M. Sohrabi; Direct Observation of Low-Salinity Water Effect: Relationship Between Micro-Dispersion Formation and Wettability Alteration. Society of Petroleum Engineers Middle East Oil \& Gas Show and Conference, 6-9 March, Manama, Kingdom of Bahrain; SPE183695-MS; 2017.

5. P. Mahzari, M.Sohrabi; Impact of Micro-Dispersion Formation on Effectiveness of Low Salinity Waterflooding; IOR 2015 - 18th European Symposium on Improved Oil Recovery, Dresden, Germany - 14-16 April 2015.

6. V. Alvarado, M. M. Bidhendi, G. Garcia-Olvera, B. Morin, J. S. Oakey; Interfacial Visco-elasticity of Crude oil - brine: an Alternative EOR Mechanism in Smart Waterflooding. Society of Petroleum Engineers Improved Oil Recovery Symposium, 12-16 April, Tulsa, Oklahoma, USA, SPE-169127-MS, 2014.

7. B. Morin, Y. Liu, V. Alvarado and J. Oakey ; A Microfluidic Flow Focusing Platform to Screen the Evolution of Crude Oil Brine Interfacial Elasticity. Lab on a Chip, 16, 3074-3081; 25th May 2016.

8. J. Gad; Zur Lehre von der Blutrache. Arch Anat Physiol, 181$192 ; 1878$.

9. S. Bochner de Araujo, M. C. Merola, D. Vlassopoulos, and G. G.Fuller; Droplet Coalescence and Spontaneous Emulsification in the Presence of Asphaltene Adsorption; Langmuir, 33(40), 1050110510; September 9th 2017.

10. P. S. Silva, S. Zhadanov, V. M. Starov, R. G. Holdich ; Spontaneous Emulsification of Water in Oil at Appreciable Interfacial Tensions. Colloids and Surfaces A: Physicochemical and Engineering Aspects, 521, 141-146; 2017.

11. G. Quincke; Ueber Emulsionbildung und den Einfluss der Galle bei der Verdauung. Plüger Archiv für die Physiologie; Volume 19, Issue 1, 129-144; 1879.

12. L. Gurwitsch; Wissenschaftliche Grundlagen der Erdöle Bearbeitung. p.20o. Translation by H. Moore (1932), 430. London: Chapman and Hall, Ltd - 1913.

13. J. T. Davies, E. K. Rideal; Interfacial Phenomena; Journal of Electrochemical Society, volume 109, issue 7, 175C; 1962.

14. K. J. Ruschak, C. A. Miller; Spontaneous Emulsification in Ternary Systems with Mass Transfer. Ind. Eng. Chem. Fundamental, 11(4), 534-540; 1962.

15. R. Granek, R. C. Ball, M. E. Cates; Dynamics of Spontaneous Emulsification. Journal of Physic II France; 3, 829-849; 1993.

16. H. Tan, C. Diddens, A. A. Mohammed, J. Li, M. Versluis, X.

Zhang, D. Lohse; Microdroplet Nucleation by Dissolution of a Multicomponent Drop in a Host Liquid; Jornal of fluid mechanics, 870, 217-246; 2019.

17. S.A. Vitale, J. L. Katz; Liquid Droplet Dispersions Formed by Homogeneous Liquid-Liquid Nucleation: "The Ouzo Effect"; Langmuir, 19 (10), 4105-4110; 2003

18. C. V. Sternling, L.E Scriven; Interfacial Turbulence: Hydrodynamic Instability and the Marangoni Effect. A.I.Ch.E. Journal - December, 514 - 523; 1959.

19. E. Ruckenstein, C. Berbente; The Occurence of Interfacial Turbulence in the Case of Diffusion Accompanied by Chemical Reaction. Chemical Engineering Science; Volume 19, Issue 5, 329347; May 1964

2o. E. Rubin, C. J. Radke; Dynamic Interfacial Tension Minima in Finite Systems. Chemical Engineering Science, Volume 35, Issue $5,1129-1138 ; 1980$.

21. J. Rudin, D. T. Wasan; Mechanisms for Lowering of Interfacial Tension in Alkali/acidic Oil Systems. Part II. Theoretical studies; Colloids and Surfaces, Volume 68, Issues 1-2, 81-94; 1992.
22. T. Dabros, A. Yeung, J. Maslijah, J. Czarnecki; Emulsification Through Area Contraction. Journal of Colloid and Interface Science; Volume 210, Issue 1, 222-224; 1 February 1999.

23. W. B. Bartels, H. Mahani, S. Berg, R. Menezes, J. A. Van Der Hoeven, A. Fadili; Oil Configuration Under High Salinity and Low Salinity Conditions at Pore Scale: a Parametric Investigation by Use of a Single Channel Micromodel; Society of Petroleum Engineers (SPE), SPE-181386-PA; October 2017.

24. S. B. Fredriksen, A. U. Rognmo, K. Sandengen, M. A. Ferno; Wettability Effects on Osmosis as an Oil-Mobilization Mechanism during Low-Salinity Waterflooding. Society of Petrophysicists and Well-Log Analysts, vol. 58, n1, 28-35, SPWLA2017-v58nia3; 2017.

25. S. B. Fredriksen, A. U. Rogmo, M. A. Ferno; Pore-Scale Mechanisms during Low Salinity Waterflooding: Oil Mobilization by Diffusion and Osmosis. Journal of petroleum science and engineering 163 (2018) 650-66o; 2017.

26. N. Passade-Boupat, M. Rondon Gonzalez, C. Hurtevent, B. Brocart, T. Palermo; Risk Assessment of Calcium Naphthenates and Separation Mechanisms of Acidic Crude Oil. Society of Petroleum Engineers International Conference on Oilfied Scale, 30-31 May, Aberdeen, UK; SPE-155229MS; 2012.

27. M. L. Chacon Patino, S. M. Rowland and R. P. Rodgers; Advances in Asphaltene Petroleomics. Part 1: Asphaltenes are Composed of Abundant Island and Archipelago Structural Motifs; Energy \& Fuels, 31(12), 13509-13518; 2017.

28. J. Kirchnerova and G. C. B. Cave; The Solubility of Water in Low Dielectric Solvent. Canadian Journal Chem 54(24), 39093916; 1976

29. D. S. Khvostichenko, S. I. Andersen, and A. I. Viktorov; Solubility and Binding of Water in Toluene Solutions of Asphaltenes; Russian Journal of Applied Chemistry, Volume 77, Issue 6, 1013-1018; June 2004 .

30. E. Y. Sheu; Petroleum Asphaltene - Properties, Characterization, and Issues; Energy Fuels, 16(1), 74-82; June 2004.

31. M. Fossen, H. Kallevik, K. D. Knudsen, and J. Sjöblom; Asphaltenes Precipitated by a Two-Step Precipitation Procedure. 1 Interfacial Tension and Solvent Properties; Energy Fuels, 21(2), 1030-1037; 2007.

32. B. Kumar; Effect of Salinity on the Interfacial Tension of Model and Crude Oil Systems; Master Thesis - department of chemical and petroleum engineering, Calgary, Alberta; 2012.

33. Dominique Langevin, Jean-François Argilier, Interfacial Behavior of Asphaltenes; Advances in Colloid and Interface Science; 233, 83-93; 2016.

34. Y. M. Ganeeva, T. N. Yusupova, G. V. Romanov; Asphaltene Nano-Aggregates: Structure, Phase Transitions and Effect on Petroleum Systems; Russian Chemical Reviews, 8o (10), 993 $1008 ; 2016$.

35. J. Duboué, M. Bourrel, T. Dusautoir, E. Santanach-Carreras, A. Klimenko, N. Agenet, N. Boupat-Passade, F. Lequeux; Relevance of Water/Oil Interfacial Structure to Low Salinity Oil Recovery Process; IOR 2019 - 20 $0^{\text {th }}$ European Symposium on Improved Oil Recovery. 
